\title{
Potential Contribution of Dark-Septate Endophytic Fungus Isolated From Pulau Dua Nature Reserve, Banten on Growth Promotion of Chinese Cabbage
}

\author{
Rida Oktorida Khastini* and Roihatul Jannah \\ Department of Biology Education, Faculty of Teacher \\ Training and Education \\ University of Sultan Ageng Tirtayasa \\ Jl Raya Jakarta Km 4 Pakupatan Serang Banten \\ *rida.khastini@untirta.ac.id
}

\begin{abstract}
Root endophytic fungi are found in natural ecosystems, but little is known about their impact on plant growth. This study reports the impact of the three isolates of dark septate endophytic fungi isolated from Pulau Dua Sanctuary, Banten on its potential activity in Chinese cabbage growth. In vitro assay was performed to analyze the contribution of those isolates on the growth promotion of Chinese cabbage. The results indicate that Chinese cabbage seedlings inoculated with the Humicola sp. isolate compared to those inoculated with Aureobasidium sp. and Basipetospora sp, showed better response in plant growth and the increased biomass was two times higher. The analysis regarding the effect of $\mathrm{pH}$ on the growth of the plants showed a significant influence of Humicola sp.treatment on acidic-neutral but not alkaline conditions. The Humicola sp. isolate could utilize Val, Leu and Phe, but Leu was the most effectively used amino acid. The results suggest the occurrence of fungal utilization of the amino acids by the fungus and subsequent transfer of $\mathbf{N}$ to the host plant. In addition, three isolates of Humicola sp, Aureobasidium sp. and Basipetospora sp, can produce auxin-like compound in the liquid culture in the presence of tryptophan.
\end{abstract}

Keywords : Amino acid, auxin, dark septate endophytic fungi, pH, plant growth promotion

\section{INTRODUCTION}

The optimization of crop production can be assisted through the incorporation into the plants the maximum amount of available fertilizer nutrients during the growth stage. Unfortunately, losses of applied fertilizer which can be attributed in a large part to low efficiency of plant nutrient uptake, lead to the contamination of surface and ground water. In fact, fertilizer leaching has been seen as inevitable in agriculture production [1, 2, 3, 4] Therefore, reducing the negative impacts of chemical fertilizers and the use of low chemical input systems are currently being promoted. The ideal agronomic system should improve nutrient-use efficiency through a combination of natural and artificial plant nutrients for increased crop productivity in an efficient and environmentally responsible manner that will not sacrifice the productivity of future generation [5].

In nature, abundant microorganisms flourish in soil, especially in the rhizosphere of plants. It is well known that a considerable number of bacterial and fungal species possess functional relationships and constitute a holistic system within plants. These microorganisms confer beneficial effects on plant growth [6]. There is well documented evidence that beneficial microorganisms participate in many key ecosystem processes such as those involved in the biological control of plant pathogens, nutrient cycling and the establishment of seedling nursery system. Therefore, these systems deserve particular attention for use in agriculture or forestry [7].

Among the most influential members of the soil microbiota are the mycorrhizal fungi, which are responsible for establishing mycorrhizas with most of the vascular plant species on earth [8]. Mycorrhizas are symbiotic associations established between soil fungi and most vascular plants, where both partners exchange nutrients and energy [9]. It is now widely accepted that mycorrhizal symbioses are fundamental for improved plant nutrition and health and soil quality [10]. Plant growth-promoting fungi (PGPF) are ubiquitous soil fungi including rhizospheric non-symbiotic beneficial fungi from the Deuteromycetes and non phatogenic soil-borne filamentous fungi that have beneficial effects on plants [11]. Studies of PGPF have focused on the mechanisms behind plant growth stimulation. PGPF have been reported to produce substances such as plant hormones [12], to allow plants to utilize decomposing organic matter through mineral solubilization [13] and to suppress plant pathogens in the rhizosphere through antagonistic mechanisms. Endophytic fungi are also considered to be mutualists that contribute to plant growth. Among the endophytic fungi are a group called dark septate endophytic fungi (DSE) which are characterized by their morphology of melanised, septae hyphae and sometimes produce a structure like microsclerotia. This group is likely paraphyletic and contain conidial as well as sterile fungi 
that colonize roots intracellularly or intercellularly, also confer the ability to improve plant performance through enhanced nutrient uptake, and increased ability to withstand adverse environmental conditions [14]. This growth promoting effect is at least in part due to the production of plant growthpromoting hormones, such as indole-3-acetic acid (IAA) [15]. Furthermore, DSE fungi can protect host plants, suppress plant diseases and increase their tolerance against pathogens directly and indirectly by producing antifungal metabolites, fungal parasitism or inducing plant systemic resistance $[16,17,18]$.

This paper evaluates a DSE fungus isolated from Pulau Dua Nature Reserve, Banten as a potential biofertilizer. Pulau Dua nature reserve which is located in Banten Bay North Coast Banten Province is one of the wetland areas which has been designated as the main area for conservation of many species of birds and migratory birds since 1937 [19, 20]. It is a lowland with total area of 30 ha.Vegetation that grows in the area is a mangrove community, $60 \%$ is dominated by Rhizopora apiculata and Avicenia marina in the southern and eat part of the island respectively. Therefore, in vitro experiments were carried out to observe potential contribution and the effect of DSE isolates from Pulau Dua nature reserve on the growth promotion of Chinese cabbage in order to elucidate the promotion mechanism.

\section{MATERIALS AND METHODS}

The research conducted in Laboratory of Biology Education, Faculty of Teacher Training and Education University of Sultan Ageng Tirtayasa during FebruaryOctober 2017.

\section{Fungal isolates}

Three DSE isolates from Pulau Dua Nature Reserve selected from the culture collection of the Laboratory of Biology Education, Faculty of Teacher Training and Education, University of Sultan Ageng Tirtayasa, were tested in this study. All the isolates belong to different species and include: Aureobasidium sp. Basipetospora sp and Humicola sp. To prepare inoculum, the isolate was grown on oatmeal agar (OMA) [oatmeal, $10 \mathrm{~g} \mathrm{~L}^{-1}$ and Bacto agar, $18 \mathrm{~g} \mathrm{~L}^{-1}$ ] enriched with $\left[\mathrm{MgSO}_{4} \cdot 7 \mathrm{H}_{2} \mathrm{O}, 1 \mathrm{~g} \mathrm{~L}^{-1} ; \mathrm{KH}_{2} \mathrm{PO}_{4}, 1.5 \mathrm{~g} \mathrm{~L}^{-1}\right.$; and $\mathrm{NaNO}_{3}, 1 \mathrm{~g} \mathrm{~L}^{-1}$ ] in 90-mm diameter Petri dishes.

\section{In vitro assay on DSE isolates growth promotion of Chinese cabbage}

The three isolates of DSE were used to inoculate Chinese cabbage (Brassica campestris L.). The seeds were surface sterilized by immersion in a $70 \%$ ethanol solution for $1 \mathrm{~min}$ and sodium hypochlorite (1\% available chlorine) for $5 \mathrm{~min}$. The seeds were subsequently rinsed three times with sterilized distilled water. The seeds were dried overnight and placed on $1.5 \%$ Bacto water agar in Petri dishes. After 2 days, the axenically grown seedlings were transplanted, three seedlings per plate, onto growing fungal colonies on the OMA medium. The seedlings transplanted onto non-inoculated media were used as controls, and all of the samples were placed into sterile culture bottles and incubated for 2 weeks at room temperature with $18 \mathrm{~h}: 6 \mathrm{~h}$ (L:L) regime at radiant flux density of $74 \mu \mathrm{mol}$ $\mathrm{m}^{-2} \mathrm{~s}^{-1}$. All experiments were conducted using the axenic culture systems with agar, thus, no contamination by other microbe was observed in this study. Three replicates were used in this experiment.

\section{Determination of growth and symbiotic parameters}

At harvest time, 3 weeks after planting, Chinese cabbage root systems were separated from the shoots and the dry weights were recorded after drying at $60^{\circ} \mathrm{C}$. For fungal colonization analysis, roots were cleared in $10 \% \mathrm{KOH}$ at $80^{\circ} \mathrm{C}$ for $20 \mathrm{~min}$, neutralized in $1 \% \mathrm{HCl}$ at $80^{\circ} \mathrm{C}$ for $20 \mathrm{~min}$ and stained with $0.05 \%$ cotton blue in $50 \%$ acetic acid. Stained roots were mounted on a slide and observed under a light microscope. Roots were checked for colonization by the fungi. Stained roots were examined along grid lines to estimate the percentage of colonization. Each grid cell was designated as either colonized or non-colonized [21]. Data were analysed with one-way analysis of variance (ANOVA). Differences among treatment means were detected with a Tukey HSD test which was carried out with SPSS software (SPSS for Windows 11.5).

\section{pH effect on the growth of plants}

To test the effect of $\mathrm{pH}$ on the growth of Chinese cabbage seedlings inoculated with three isolates of DSE, OM medium supplemented with nutrients was prepared with $10 \mathrm{~g}$ oatmeal, $18 \mathrm{~g}$ Bacto agar, Difco, $1 \mathrm{~g} \mathrm{MgSO}_{4} \cdot 7 \mathrm{H}_{2} 0,1.5 \mathrm{~g}$ $\mathrm{KH}_{2} \mathrm{PO}_{4}$ and $1 \mathrm{~g} \mathrm{NaNO}_{3}$ per liter) in $55 \mathrm{~mm}$ diameter Petri dishes. The $\mathrm{pH}$ of the medium was adjusted to 3.0, 6.0 and 9.0 using $1 \mathrm{~N} \mathrm{HCl}$ and $1 \mathrm{~N} \mathrm{NaOH}$. The three isolates of Aureobasidium sp. Basipetospora sp and Humicola sp. were grown in these media for two weeks at room temperature. Axenic seedlings of Chinese cabbage were prepared as described previously. Three axenic seedlings were transplanted to each fungal colony in the culture bottles. All seedlings were incubated in a growth chamber at $23^{\circ} \mathrm{C}$ under a 16:8 L:D cycle, approximately $180 \mu \mathrm{mol} \mathrm{m} \mathrm{m}^{-2} \mathrm{~s}^{-2}$ ). After 30 days, dry weights of the seedlings were measured. The experiments were repeated three times.

\section{Nitrogen utilization assays}

To test the nitrogen use of Chinese cabbage seedlings inoculated with three isolates of DSE, basal agar OM medium was prepared as earlier stated. Different nitrogen sources $\left[\mathrm{NaNO}_{3}\right.$, and $20 \%$ of amino acids (Val, Leu and Phe)] were added to the medium. Each amino acid was filter-sterilized and amended with autoclaved basal medium. Glucose was added 
and adjusted to a final C:N ratio of 10:1, depending on each $\mathrm{N}$ source. The growth of Chinese cabbage seedlings on these media was evaluated using the same methods as for the $\mathrm{pH}$ study earlier.

\section{Quantification of auxin-like compound (IAA) production}

DSE isolates were grown on potato dextrose broth amended with $1000 \mu \mathrm{g} \mathrm{ml} \mathrm{m}^{-1}$ L-tryptophan and incubated at $30^{\circ} \mathrm{C}$ on a rotary shaker (Taitec Bio Shaker BR-300 LF, Japan) at $150 \mathrm{rpm}$. After 1 week incubation, $1.5 \mathrm{ml}$ of each culture isolate was centrifuged at $15,000 \mathrm{rpm}$ for $15 \mathrm{~min}$, and 1 $\mathrm{ml}$ of supernatant was mixed with $2 \mathrm{ml}$ of Salkowski's reagent ( $2 \% 0.5 \mathrm{M} \mathrm{FeCl}_{3}$ in $35 \%$ perchloric acid) and incubated at room temperature for $20 \mathrm{~min}$. The absorbance was measured at $540 \mathrm{~nm}$ using a spectrophotometer. The same treatment was conducted every week during 5 weeks incubation. A standard curve was calculated for comparison to determine IAA production by isolates using IAA (Wako, Japan) as a standard. Three replicates were used for each treatment.

\section{RESULTS AND DISCUSSION}

In the present study, we demonstrated that DSE fungi isolated from Pulau Dua Nature Reserve have the ability to enhance Chinese cabbage and potential to be applied as bioferilizer agent in the future. Previously Aureobasidium sp., Basipetospora sp, and Humicola sp. isolated within 15 days of placing root segments of mangrove plant, Avicena marina on the medium. The Colonies of 3 isolates, Aureobasidium sp., Basipetospora sp , and Humicola sp. and colonial growth on OMA medium were similar (Fig. 1).

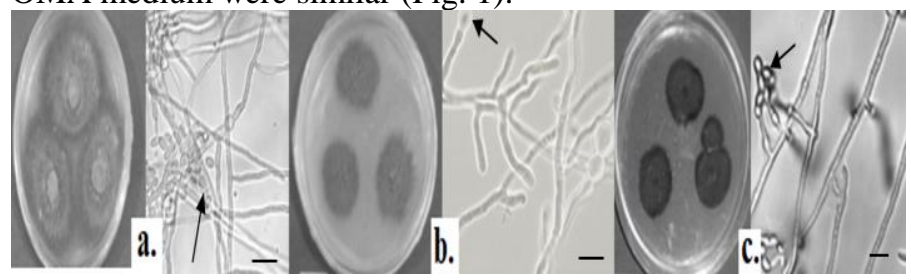

Fig. 1. Dark septate endophytic fungi isolates colony and conidia. A. Aureobasidium sp., Basipetospora sp , and Humicola sp. Arrow indicates a conidia. Bars $10 \mu \mathrm{m}$

Aureobasidium sp colonies becoming dark occasionally with sparse aerial mycelium hyphae with septate, hyaline and thinwalled when young, frequently becoming melanized and thickwalled with age, may develop into chlamydospores. Conidiogenous cells undifferentiated, intercalary, rarely terminal, mostly on hyaline hyphae, producing conidia. Humicola sp colonies were glabrous to slightly cottony in the center, flat, and cream to pale brown, becoming brown to dark brow. The fungi produce phialidic conidiahyaline, and obovate, with slightly truncate ends, arranged in long dry chains on the apex of the conidiogenous cells

\section{In vitro assay of DSE isolates growth of Chinese cabbage}

The inoculation of Aureobasidium sp. and Basipetospora sp isolates had no visible effect on the growth of Chinese cabbage compared with the uninoculated control, whereas Humicola sp. inoculated plant showed visible increases in growth. Inoculation of Chinese cabbage with Humicola sp. isolate in vitro gave the highest shoot dry weight (Table 1) which was significantly greater than the uninoculated control, while Aureobasidium sp. and Basipetospora sp showed no significant differences compared with the control. The mean root dry weight ranged from 7.8 for the Basipetospora sp. inoculated plants to $14.88 \mathrm{mg}$ for the uninoculated control but did not differ between treatments (Table 1).

Table 1. The effect of DSE isolates inoculation on Chinese cabbage growth, and fungal colonization.

\begin{tabular}{|c|c|c|c|}
\hline \multirow{2}{*}{ Treatment } & \multicolumn{2}{|c|}{ Dry weight (mg) } & \multirow{2}{*}{$\begin{array}{c}\text { Fungal } \\
\text { colonization } \\
(\%) \\
\end{array}$} \\
\hline & Shoot & Root & \\
\hline Control & $\begin{array}{c}26.68 \pm \\
6.23^{\mathrm{a}}\end{array}$ & $\begin{array}{c}14.881 \pm \\
5.15^{\mathrm{b}}\end{array}$ & $0^{\mathrm{a}}$ \\
\hline $\begin{array}{l}\text { Aureobasidium } \\
\text { sp. }\end{array}$ & $\begin{array}{c}27.84 \pm \\
5.13^{\mathrm{a}}\end{array}$ & $\begin{array}{c}8.125 \pm \\
1.27^{\mathrm{a}}\end{array}$ & $38.2 \pm 8.38^{b}$ \\
\hline Humicola sp. & $\begin{array}{c}36.38 \pm \\
15.90^{\mathrm{b}}\end{array}$ & $\begin{array}{c}12.912 \pm \\
1.35^{\mathrm{a}}\end{array}$ & $66.0 \pm 5.83^{c}$ \\
\hline Basipetospora sp. & $\begin{array}{c}27.58 \pm \\
6.34^{\mathrm{a}}\end{array}$ & $\begin{array}{c}7.813 \pm \\
1.20^{\mathrm{a}}\end{array}$ & $42.8 \pm 3.25^{b}$ \\
\hline
\end{tabular}

Values are the mean of three replicates \pm the standard error. Values with different letters within column differ significantly $\mathrm{p}<0.05$.

The roots inoculated with the fungal isolates were stained with $0.05 \%$ cotton blue to examine the degree of colonization. The root colonization pattern was nearly similar in Humicola sp and Aureobasidium sp., but the degree of fungal colonization of Aureobasidium was the lowest compared with that of Humicola sp.and Basipetospora sp. Figure 2 shows the dense networks of hyphae observed on the entire surface of Chinese cabbage roots which were colonized by Humicola sp. Intercellular infections with Humicola sp. hyphae were observed in semi-thin cross sections of the root. Although the intercellular hyphae developed parallel to the longitudinal root axis, they were restricted and present only in the cortical cells. The fungus did not invade the vascular cylinder.

\section{pH effect on the growth of Chinese cabbage}

In this research, three different $\mathrm{pH}$ media $(3.0,6.0$ and 9.0) were chosen to provide a $\mathrm{pH}$ range from acidic to alkaline conditions. The effects of DSE isolates were observed on plant growth. Inoculation with Humicola sp. significantly increased plant dry weight compared with the uninoculated control at $\mathrm{pH}$ 3.0 and 6.0 but not at pH 9.0 (Fig. 2). The other two isolates, 
Aureobasidium sp. and Basipetospora sp. did not promote plant growth compared with the control at any of $\mathrm{pH}$ levels.

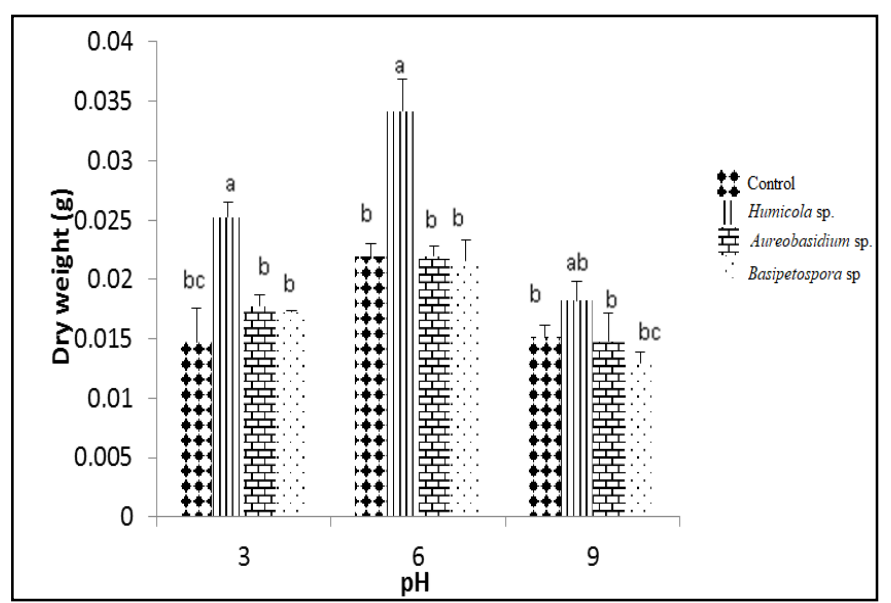

Fig. 2 The effect of $\mathrm{pH}$ (acid, neutral and alkaline) on the growth of Chinese cabbage inoculated by DSE isolates. Values with different letters differ significantly at $p<0.05$.

Treatment with Humicola sp. effectively promoted plant growth under acidic and neutral conditions. Changes in $\mathrm{pH}$ can also cause many other abnormalities in the soil, particularly the activity and availability of mineral elements for plant absorption [22]. According to [23] soil acidity and alkalinity cause severe stress in agriculture worldwide and are important cause of yield and quality reduction in crops. Thus, the presence of DSE fungi may enable plant growth in conditions where nutrients are unavailable. When the external $\mathrm{pH}$ is up to 7.5, a passive influx of $\mathrm{OH}^{-}$ions occurs, and the cytoplasmic $\mathrm{pH}$ increases with increasing external $\mathrm{pH}$. [24] suggesting that the external $\mathrm{pH}$ could directly influence the

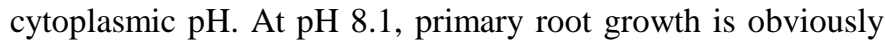
suppressed [25]. High-pH conditions (alkaline $\mathrm{pH}$ ) can have considerable effects on fungi and its adaptation to various environmental conditions. Many researchers have reported relatively narrow ranges of $\mathrm{pH}$ for the presence or activity of specific AM fungi in soils [26]; however, information concerning AM fungal adaptability over broad soil and growth media $\mathrm{pH}$ ranges is limited.

\section{Nitrogen source}

Chinese cabbage seedlings inoculated with three isolates of DSE were transplanted onto agar media containing three different nitrogen $(\mathrm{N})$ sources, including $\mathrm{NaNO}_{3}$, and three different amino acids (Val, Leu and Phe). Figure 4 shows that Chinese cabbage without endophytic fungi inoculation could use $\mathrm{NaNO}_{3}$ as nitrogen source, but could not use amino acids (Val, Leu and Phe) as effectively, as demonstrated by their dry weight, which was significantly decreased in the amino acid treatment. The growths of Leu-treated plants inoculated with the Humicola $\mathrm{s}$ isolate were significantly different and showed the optimal growth followed with the Val compared to the control. When Phe was amended in the medium, the plant inoculated with Humicola $\mathrm{s}$ isolate was significantly improved but not for plants inoculated with Aureobasidium sp. and Basipetospora sp.

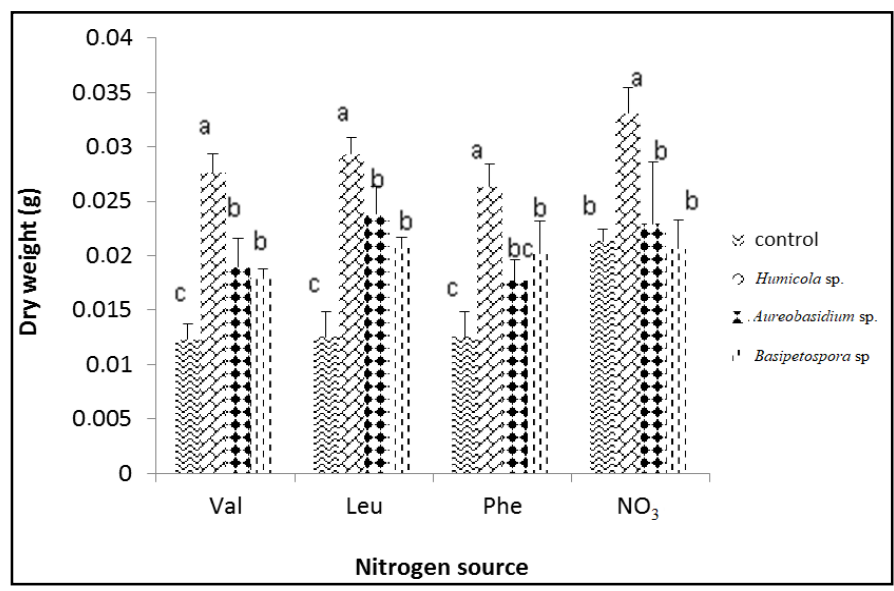

Figure 3. The effect of amino acids as a nitrogen source on the growth of Chinese cabbage. $\mathrm{NO}_{3}$ was used as a control. Values with different letters within each nitrogen source differ significantly at $\mathrm{p}<0.05$.

In a previous study, [21] showed that the Chinese cabbage could not effectively use an organic nitrogen source such as Gly, Leu, Phe and Val, but H. chaetospira-treated plants were able to use all four amino acids effectively and the plant dry weight was increased. In the present study Humicola sp. the three amino acids (Val, Leu and Phe), with Leu as the most effective. The other two isolates showed a similar response in the utilization of Leu, as demonstrated through the increased dry weight. These results suggest that the fungal utilization of amino acids and subsequent transfer of $\mathrm{N}$ to the host plant occurred. The release of ammonium $\left(\mathrm{NH}_{4}{ }^{+}\right)$into the culture medium might explain the positive influence of the fungus on plant growth. Without fungal inoculation, Chinese cabbage could not use Val, Leu and Phe. Indeed, in several plants, the end product from amino acids metabolism inhibited growth [27]. Whether the relationship between these amino acids and DSE inoculation significantly have effects on growth of Chinese cabbage seedlings has not been determined.

\section{Auxin-like compound production analysis}

The production of an auxin-like compound by DSE isolates was detected, after a one-week incubation, with Humicola sp. and Aureobasidium sp. and IBA K45. It reached a maximum level after 3 weeks and subsequently decreased slowly as shown in Figure 4. In the absence of tryptophan, the three isolates did not produce the auxin-like compound. However, with tryptophan, the estimated concentration was 50 
to 280,25 to 75 , and 29 to $34 \mu \mathrm{g} \cdot \mathrm{ml}^{-1}$ for Humicola sp . Aureobasidium sp . and Basipetospora sp., respectively.

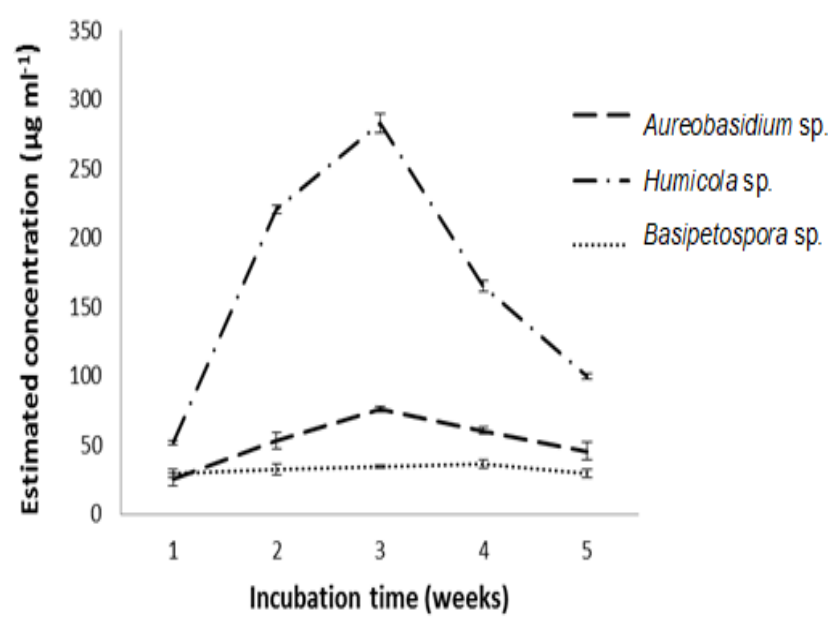

Fig. 4 Effect of the incubation period on auxin-like compound production by DSE isolates. The data are given as the means of three replicates.

The different ability of DSE isolates to promote plant growth was demonstrated, as the Humicola sp. isolate produced more auxin-like compound than Aureobasidium sp. and Basipetospora sp. also showed the greatest plant biomass. Previous research have been reported on Humicola sp. Aureobasidium sp and Basipetospora sp. as endophytic fungi colonized and give positive response on Oryza sativa [28], Brassica chinensis [29], common bean [30] respectively. [31] and [32] observed a similar response for Piriformospora indica which also produced auxin. Auxin is known as a plant growth hormone in flowering plants that play an important role in root growth, tropism, apical dominance, and plant senescence and is involved in cell expansion, division, and differentiation [33]. The most important member of the auxin family is IAA. Bacteria and fungi have been reported to produce a substance similar to auxin. [34] demonstrated role of auxin signaling for plant growth promotion by Trichoderma virens. In addition, [35] reported that one of the members of the dark-septate endophytic fungi, Piriformospora indicai, which have been shown to improve plant growth also, has the capacity to produce IAA. Previous studies have also indicated that DSE fungi enhance plant growth through the production or induction of plant growth hormones without any facilitation of host nutrient uptake and metabolism [36, 37]. The auxinlike compound produced by DSE isolates was dependent on incubation period and tryptophan availability. The fungus does not expend energy to synthesize the amino acid because the plant tissue provided the tryptophan. In return DSE isolates will convert tryptophan to IAA and confers a benefit to the plant which can be considered as mutual interaction.

\section{CONCLUSIONS}

Dark Septate Endophytic fungal associations with crops offer benefits such as the promotion of plant Growth. Our findings indicated that Chinese cabbage inoculated with DSE fungi increased in biomass. DSE fungi utilizated of the amino acids transfered to the host plant and produce auxin-like compound. However, a more detailed understanding of biochemical and molecular DSE-tomato interactions is still needed. This study is still at an experimental level, and moving from the lab or greenhouse to the field should be encouraged to determine the effectiveness of DSE isolates for further application in plant responses

\section{ACKNOWLEDGMENT}

The study was conducted with financial support by a Grant-inAid for Fundamental Research from the Ministry of Research, Technology and Higher Education of the Republic of Indonesia (No. 525/UN43.9/PL/K). The authors would also like to acknowledge all of the students of biology education at Sultan Ageng Tirtayasa University who contributed to the study in various ways.

\section{REFERENCES}

[1] Ottman, M. J., \& Pope, N. V. Nitrogen fertilizer movement in the soil as influenced by nitrogen rate and timing in irrigated wheat. Soil Science Society of America Journal 64, 1883-1892. 2000.

[2] Steinshamn, H., Thuen, E., Bleken, M.A., Brenoe, U.T., Ekerholt, G., \& Yri, C. Utilization of nitrogen (N) and phosphorus (P) in an organic dairy farming system in Norway. Agriculture, Ecosystems and Environment 104, 509-522. 2004.

[3] Kleinman, P. J. A., Wolf, A. M., Sharpley, A. N., Beegle, D. B., \& Saporito, L. S. Survey of waterextractable phosphorus in livestock manures. Soil Science Society of America Journal 69, 701-708. 2005.

[4] Ohno, T., Griffin, T. S., Liebman, M., \& Porter, G. A. Chemical characterization of soil phosphorus and organic matter in different cropping systems in Maine, USA. Agriculture, Ecosystems and Environment 105, 625-634. 2005.

[5] Hirel, B.; Tétu, T.; Lea, P.J.; Dubois, F. Improving Nitrogen Use Efficiency in Crops for Sustainable Agriculture. Sustainability 3, 1452-1485. 2011.

[6] Vessey, J. K. Plant growth promoting rhizobacteria as biofertilizers. Plant Soil 255: 571-586. 2003) 
[7] [Kumar BL, Gopal DV. Effective role of indigenous microorganisms for sustainable environment. 3 Biotech. 5(6):867-876. doi: 10.1007/s13205-015-0293-6. 2015

[8] Landis FC, Gargas A, Givnish TJ Relationships among arbuscular mycorrhizal fungi, vascular plants, and environmental conditions in oak savannas. New Phytol 164:493-504. 2004

[9] Brundrett, M. C. Coevolution of roots and mycorrhizas of land plants. Tansley review 134. New Phytologist 154, 275-304. 2002

[10] Barea, J. M., Calvet, C., Estaun, V., \& Camprubi, A. Biological control as a key component in sustainable agriculture. Plant and Soil 185, 171-172. 1996.

[11] J.M. Raaijmakers, T.C. Paulitz, C. Steinberg, C. Alabouvette, Y. Moënne-Loccoz.The rhizosphere: a playground and battlefield for soilborne pathogens and beneficial microorganisms Plant Soil, 321. pp. 341361. 2009

[12] Koitabashi, M., New biocontrol method for parsley powdery mildew by the antifungal volatiles-producing fungus Kyu-W63. Fungal Dis., 71: 280-284. 2005.

[13] M.S. Reddy, S. Kumar, K. Babita Biosolubilization of poorly soluble rock phosphates by Aspergillus tubingensis and Aspergillus niger Bioresource Technol., 84, pp. 187-189. 2002

[14] Mandyam, K., \& Jumpponen, A. Seeking the elusive function of the root-colonising dark septate endophytic fungi. Studies in Mycology 53, 173-189. 2005.

[15] Khan, A., Hamayun, M., Kang, S., Kim, Y., Jung, H., Lee, J., \& Lee, I. Endophytic fungal association via gibberellins and indole acetic acid can improve plant growth under abiotic stress: an example of Paecilomyces formosus LHL10. BMC Microbiology 12, 3. 2012.

[16] Samuel, M. A., Miles, G.P., \& Ellis, B.E. Ozone treatment rapidly activates MAP kinase signalling in plants. Plant Journal 22, 367-376. 2000.

[17] Campanile, G., Ruscelli, A., \& Luisi, N. Antagonistic activity of Endophytic fungi towards Diplodia corticola assessed by in vitro and in planta test. European Journal of Plant Pathology 117, 237-246. 2007.

[18] Lestari, S. M., Hidayat, S. H., \& Widodo. Determination of endophytic fungi as induce resistance agent of chilli pepper against pepper yellow leaf curl disease. AGRIVITA Journal of Agricultural Science, 40(2), 249- 256. http://doi.org/10.17503/agrivita.v40i2.989. 2018.

[19] Milton, R and A. Mahadi. The Bird Life of The Nature Reserve Pulau Dua. Kukila 1985 (2). Jakarta: Indonesia Ornithological Soc. 1985.

[20] Partomihardjo, T. Formasi Vegetasi di Cagar Alam Pulau Dua, Serang Jawa Barat. Media Konservasi 2 : 10-15. 1986.
[21] Usuki, F., \& Narisawa, K. A mutualistic symbiosis between a dark septate endophytic fungus, Heteroconium chaetospira, and a nonmycorrhizal plant, Chinese cabbage. Mycologia 99 (2), 175-184. 2007.

[22] Conyers, M. K., Uren, N. C., \& Helyer, K. R. Causes of changes in $\mathrm{pH}$ in acidic mineral soils. Soil Biol. Biochemistry 27, 1383-1 392. 1995.

[23] Liu. J., \& Guo, Y. The alkaline tolerance in Arabidopsis requires stabilizing microfilament partially through inactivation of PKS5 kinase. The Journal of Genetics and Genomics 38, 307-313. 2011.

[24] Gout, E., Bligny, R., \& Douce, RRegulation of intracellular $\mathrm{pH}$ values in higher plant cells. Carbon-13 and phosphorus-31 nuclear magnetic resonance studies. 1992.

[25] Yang, Y., Qin, Y., Xie, C., Zhao, F., Zhao, J., Liu, D., Chen, S., Fuglsang, A. T., Palmgren, M. G., Schumaker, K. S., Deng, X. W., \& Guo, Y. The Arabidopsis chaperone $\mathrm{J} 3$ regulates the plasma membrane $\mathrm{H}$ p-ATPase through interaction with the PKS5 kinase1. Plant Cell 22, 1313-1332. 2010.

[26] Kluber, L.A., S.R. Carrino-Kyker, D.J. Burke, K.P. Coyle, J.L. DeForest, A.N. Shaw, and K.A. Smemo. Response of mycorrhizal communities to experimental $\mathrm{pH}$ and $\mathrm{P}$ manipulation in acidic hardwood forests. PLoS ONE 7(11): e48946. DOI:10.1371/journal.pone.0048946. 2012

[27] Steinberg, R. A. Growth responses to organic compounds by tobacco seedlings in aseptic culture. Journal of Agricultural Research 758, 1-92. 1947.

[28] Naik B. S, Shashikala J., Krishnamurthy, Y. L. Study on the diversity of endophytic communities from rice (Oryza sativa L.) and their antagonistic activities in vitro, Microbiological Research,164(3), 290-296, https://doi.org/10.1016/j.micres.2006.12.003. 2009.

[29] Zhou, S., Qiu, H., Feng, C., Guo, Y., Wang, X. \& Chen, C. Impact of deltamethrin on the endophytic fungal community of a Chinese cabbage, Brassica chinensis , Chemistry and Ecology, 32:3, 259-269, DOI: 10.1080/02757540.2015.1135907. 2016.

[30] Parsa, S., García-Lemos, A. M., Castillo, K., Ortiz, V., López-Lavalle, L. A. B., Braun, J., \& Vega, F. E. Fungal endophytes in germinated seeds of the common bean, Phaseolus vulgaris. Fungal Biology, 120(5), 783790. http://doi.org/10.1016/j.funbio.2016.01.017. 2016.

[31] Singh, A., Sharma, J., Rexer, K. H., \& Varma, A. Plant productivity determinants beyond minerals, water and light. Piriformospora indica- a revolutionary plant growth-promoting fungus. Current Science 79, 101106. 2000.

[32] Varma, A., Singh, A., Sudha, Sahay, N., Sharma, J., Roy, A., Kumari, M., Rana, D., Thakran, S., Deka, D., 
Bharti, K., Franken, P., Hurek, T., Blechert, O., Rexer, K. H., Kost, G., Hahn, A., Hock, B., Maier, W., Walter, M., Strack, D., \& Kranner. I. Piriformospora indica: an axenically culturable mycorrhiza-like endosymbiotic fungus, in: Hock (Ed.) B., Mycota IX, Springer, Berlin Heidelberg, New York, pp. 123-150. 2001.

[33] Davies, P. J. Plant Hormones: Biosynthesis, Signal Transduction. Kluwer Academic Publishers. Netherlands. 2004.

[34] Contreras-Cornejo, H. A., Macías-Rodríguez, L., Cortés-Penagos, C.\&López-Bucio, J. Trichoderma virens, a plant beneficial fungus, enhances biomass production and promotes lateral root growth through an auxin-dependent mechanism in Arabidopsis. Plant Physiol 149, 1579-1592. 2009.

[35] Sirrenberg, A., Goebel, C., Grond, S., Czempinski, N., Ratzinger, A., Karlovsky, P., Santos, P., Feussner, I., \& Pawlowski, K. Piriformospora indica affects plant growth by auxin production. Physiology Planta 131, 581-589. 2007.

[36] Addy, H. D., Pieredy, M. M., \& Currah, R. S. Microfungal endophytes in roots. Canadian Journal of Botany 83, 1-13. 2005.

[37] Schulz, B., Boyle, C., Draeger, S., Römmert, A. K., \& Krohn, K. Endophytic fungi: a source of novel biologically active secondary metabolites. Mycology Research 106: 996-1004. (2002). 